\title{
Investigation of Seismic Behavior of Container Crane Structures by Shake Table Tests and Mathematical Modeling
}

\author{
C. Oktay Azeloglu, ${ }^{1}$ Ayse Edincliler, ${ }^{2}$ and Ahmet Sagirli ${ }^{1}$ \\ ${ }^{1}$ Department of Mechanical Engineering, Yildiz Technical University, 34349 Istanbul, Turkey \\ ${ }^{2}$ Department of Earthquake Engineering, Kandilli Observatory and Earthquake Research Institute, Bogazici University, \\ 34684 Istanbul, Turkey
}

Correspondence should be addressed to C. Oktay Azeloglu; azeloglu@yildiz.edu.tr

Received 24 February 2014; Accepted 16 June 2014; Published 13 July 2014

Academic Editor: Peijun Xu

Copyright ( 2014 C. Oktay Azeloglu et al. This is an open access article distributed under the Creative Commons Attribution License, which permits unrestricted use, distribution, and reproduction in any medium, provided the original work is properly cited.

\begin{abstract}
This paper is concerned with the verification of mathematical modeling of the container cranes under earthquake loadings with shake table test results. Comparison of the shake table tests with the theoretical studies has an important role in the estimation of the seismic behavior of the engineering structures. For this purpose, a new shake table and mathematical model were developed. Firstly, a new physical model is directly fixed on the shake table and the seismic response of the container crane model against the past earthquake ground motion was measured. Secondly, a four degrees-of-freedom mathematical model is developed to understand the dynamic behaviour of cranes under the seismic loadings. The results of the verification study indicate that the developed mathematical model reasonably represents the dynamic behaviour of the crane structure both in time and frequency domains. The mathematical model can be used in active-passive vibration control studies to decrease structural vibrations on container cranes.
\end{abstract}

\section{Introduction}

The 1995 Kobe Earthquake exposed the destructive effects of earthquake motions on cranes. During the earthquake, many cranes were damaged and one collapsed primarily due to spreading of support girders. Recent studies indicated that modern jumbo cranes are susceptible to damage highlighting the importance of improving the seismic performance of cranes. Seismic risk to cranes is becoming better understood. In Figure 1, the collapsed crane at the 1995 Kobe Earthquake is represented.

Some of the researches about seismic behaviour of the cranes aim to understand the behaviour of cranes under earthquake loadings while some of them aim to investigate methods to mitigate these risks. An important tool to understand the dynamic behaviour of crane structures in earthquakes is to develop a scaled physical model of the crane and perform the shake table tests.

Kanayama and Kashiwazaki [1] and Kanayama et al. [2] investigated the dynamic behavior of cranes conducting a series of shaking table tests. 1/25 scaled crane model was used for the first experiment and, for the second one, a 1/8 scaled model was used. Experiments were performed under uniaxial earthquake excitations that were applied along the direction of the boom. Real earthquake records were used during the experiments and horizontal component of the records considered which component is the most destructive. Performed experiments were focused on investigating the major failure mechanisms and monitoring the rigidity of the crane structure under dynamic loading. Soderberg and Jordan [3] identified that the risk of seismic damage has increased as crane size has increased and have provided design recommendations to mitigate the risk.

Koshab and Jacobs [4] and Jacobs et al. [5] constructed a 1/20 scaled shake table model, tested under earthquake loadings. Seismic waves are applied uniaxial horizontally along the boom. They observed the seismic performance of jumbo container cranes. Test results are compared with the finite element model and constructive precautions are suggested with respect to the results. Dynamic behaviour of 


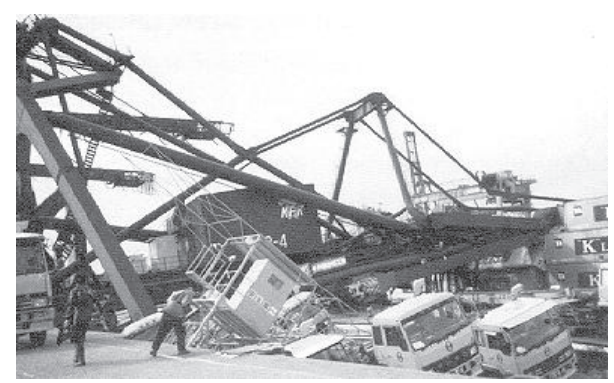

FIgURE 1: Collapsed crane at the Kobe Earthquake [21].

the wheel-rail connection of a 1/8 scaled physical model is observed using the real earthquake data on the shake table model by Kobayashi et al. [6]. The study is focused on the derailment behaviour of the cranes. They observed connection problems between wheels and rails of cranes during earthquakes.

Sugano et al. [7] researched theoretically the dynamics of crane structures under earthquake motions using different methods and also performed the shaking table tests using a 1/15 scaled crane model. Seismic waves were applied uniaxially along the boom. Horizontal components of the real earthquake records were considered. During theoretical research, the crane model was modeled as a single degree-offree-dom simple mass-spring system and also two- and threedim-ensional finite element analyses were performed.

A five degrees-of-freedom nonlinear mathematical model of gantry cranes is developed by Sagirli and Azeloglu [8]. Earthquake motions are applied horizontally along the boom uniaxial. Results obtained from mathematical model are reasonable with the scaled shake table gantry crane model. It is revealed that the developed mathematical model can be used as a gantry crane model in active vibration control studies in order to decrease the structural vibrations on the gantry cranes. By using the defined mathematical model, to decrease the structural vibrations on gantry cranes, Sagirli et al. [9] performed active vibration control studies. The results of the simulation studies show that active vibration control can be successfully performed on gantry cranes.

Azeloglu [10] developed a nonlinear mathematical model that represents the dynamic behaviour of container cranes placed on the sand foundation, proved the mathematical model with shake table tests of a physical crane model, and implemented the active vibration control. Results show that active vibration control can successfully be applied to container cranes.

Azeloglu et al. [11] developed a new six degrees-offreedom mathematical model of container cranes to compare the shake table tests results. Shake table model studies cover mitigation of the earthquake hazards using the developed isolation method. The physical model consists of the inclusion of the foundation system and the payload. From this reason, dynamics of the soil is also integrated to the developed mathematical model. Earthquake motions are applied horizontally along the boom uniaxial. Results obtained from

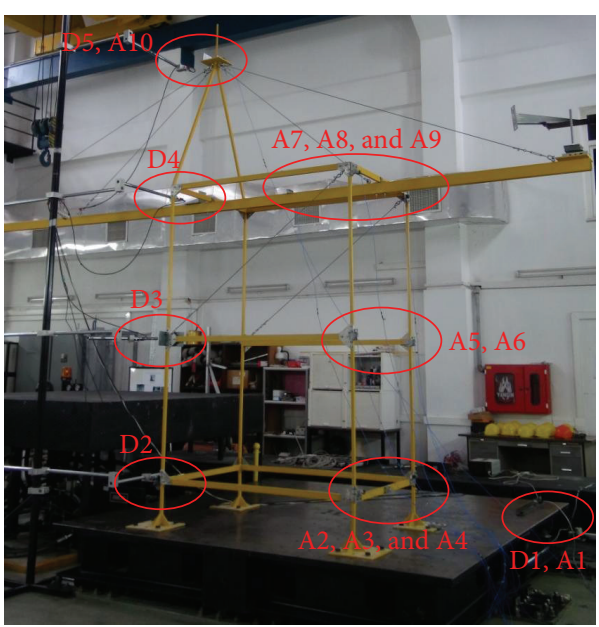

FIGURE 2: Location of the instruments on the physical model.

mathematical model are reasonable with those obtained from the shake table model.

Past studies indicate that shake table tests are an effective tool to investigate the seismic performance of crane structures under earthquake excitations. Scaled physical models of cranes are needed as well as numerical models to obtain comparable results. The main aim of this study is to develop a simple and effective mathematical model for a container crane under earthquake loadings. For this purpose, shake table and mathematical models were developed and tests were performed. A comparison between a mathematical model and a shake table model is presented. This paper consists of three main parts. The first part covers the shake table tests including the design of the shake table model and the performance of the tests. The second part includes the development of the mathematical model. In the last part, comparison and evaluation of the experimental results with the numerical results will be given.

\section{Shake Table Tests}

The design of the physical model and test setup, instrumentation, test procedure, and test results are given in the following parts.

2.1. Physical Model and Test Setup. A 1/20 scaled container crane is used in the experiments. Past studies have determined that a scaling factor of $1 / 20$ is sufficient to be able to observe the dynamic behaviour of the crane under seismic loading and to analyze the vibrations $[5,8]$. Scaling factors are selected with respect to dynamic equilibrium. The same scaling factors were used with a previous study [11]. As a main difference, given in this study, the shake table model is directly fixed on the shake table. Details of the test setup are given in Figure 2.

2.2. Instrumentation. Experimental studies were performed at Bogazici University, Kandilli Observatory and Earthquake Research Institute. The shake table used for this experiment 


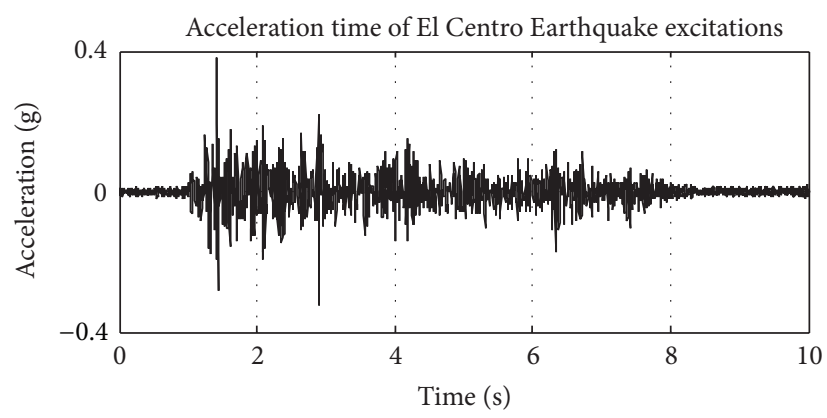

FIgURE 3: Time histories of scaled El Centro Earthquake.

TABLE 1: Frequency values of free vibration test.

\begin{tabular}{lcc}
\hline & Frequency $(\mathrm{Hz})$ & $f_{2}$ \\
$f_{1}$ & & 3.94 \\
\hline 2.36 & \\
\hline
\end{tabular}

is a uniaxial horizontal vibration shake table which is capable of carrying a maximum of 10 tons payload on the $3 \mathrm{~m} \times 3 \mathrm{~m}$ table with a maximum of $2 \mathrm{~g}$ acceleration. Earthquake records of acceleration are used in programming and controlling the shake table motions.

To determine the acceleration and displacement time histories, ten accelerometers and four displacement sensors are placed on the container crane model. The instrumentation plan is given in Figure 2. The symbol "D" shows displacement sensors while "A" shows accelerometers. A1 is placed on the shake table to measure the base acceleration, A2, A3, and A4 are at the sill beams, A5 and A6 are at the portal beams on the crane structure, A7, A8, and A9 are on the crane boom, and A10 is located at the apex. A1 works within a range of $3 \mathrm{~g}$ and the rest of the accelerometers (A2-A10) work within a range of $20 \mathrm{~g}$. D1 is placed on the shake table, D2 is at the sill beam, D3 on the portal beam, D4 on the boom, and D5 is placed at the apex. D1 and D2 are wired displacement sensors while D3, D4, and D5 are laser displacement sensors. D1 and D2 are capable of measuring the displacement within a range of 0-300 mm and the others can measure $20-400 \mathrm{~mm}$ displacements. The sampling rate of the shake table tests is 200 samples per second and the same instrumentation remained constant for all test setups.

2.3. Test Procedure and Test Results. The results of the experimental studies in frequency domain are obtained exposing the model to free vibration test. Based on the past research, it is known that the mode of vibration parallel to the crane boom is the most dangerous during an earthquake. To determine low frequencies, a rubber hammer was used to impact the model. To determine high frequencies, a steel hammer was used. The first critical frequency values for each case are considered as given in Table 1.

The 1940 El Centro Earthquake record (nisee.berkeley. edu/data/strong_motion/a.k.chopra/el_centro_data) was used as an input motion. This Earthquake motion was chosen because it is destructively well known. The ground motion history of the scaled earthquake data used during the shake table tests is shown in Figure 3.

The time histories of displacements and accelerations measured on sill beams, portal beams, boom, and apex are given in Figure 4. Table 2 represents the maximum acceleration and displacement values of the shake table test results as peak ground acceleration (PGA) and peak ground displacement (PGD) values.

\section{Mathematical Modeling}

A mathematical model of a container crane was developed to determine the dynamic behaviour of cranes during an earthquake. Researchers studied multi degree-of-freedom dynamic models of the cranes [12-15]. Four degrees-offreedom mathematical model is developed which shows dynamic behaviour of container cranes under seismic loading. The crane is modeled using spring-mass-damper subsystems. Since the destructive effect of earthquakes is a result of horizontal vibrations, the degrees-of-freedom model has been assumed to occur only in this direction [11].

Kobayashi et al. show that the wheel-rail connection in cranes can be modelled as spring and damping element [6]. The wheel-rail connection in this study is modelled as a spring and a damping element. Destructive effects of the earthquakes are primarily a result of horizontal motions, so only horizontal motions are applied. A schematic crane model with the direction of seismic loading is provided in Figure 5. The dynamic model, where $m_{1}, m_{2}, m_{3}$, and $m_{4}$ represent, in order, wheel mechanism and sill beams, portal beams, boom, and apex, respectively. In addition, $k_{1}$ and $c_{1}$ are the stiffness of the wheel-rail connections and damping, $k_{2}, k_{3}$, and $k_{4}$ are stiffness of the portal and braced frames, and $c_{2}, c_{3}$, and $c_{4}$ are damping of the portal and braced frames. $x_{0}$ is the earthquake-induced ground motion disturbance imposed on the crane structure; $x_{1}, x_{2}, x_{3}$, and $x_{4}$ are displacements for the related parts of the structure (Figure 6).

The developed dynamic model includes these assumptions. (i) The degrees-of-freedom system is horizontal. (ii) The dynamic model was developed to represent the dynamic effects on the boom uniaxially. (iii) The earthquake motions 


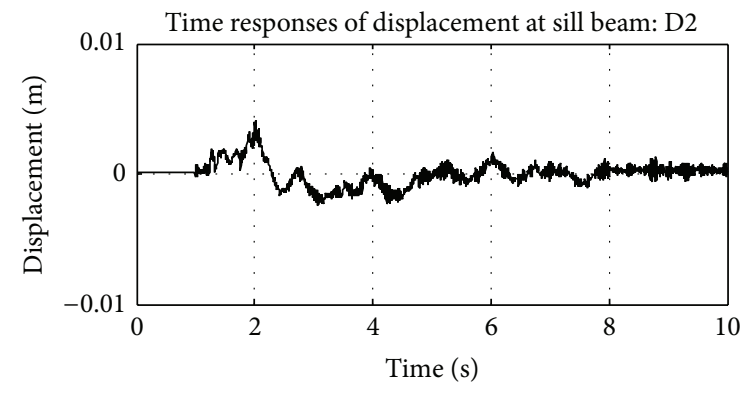

- D2

(a)

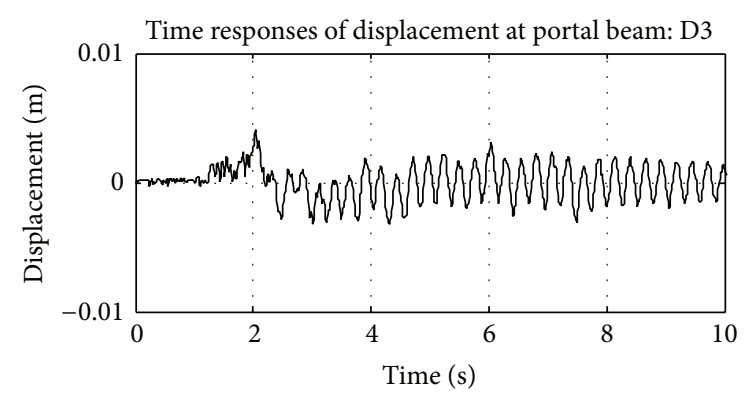

- D3

(c)

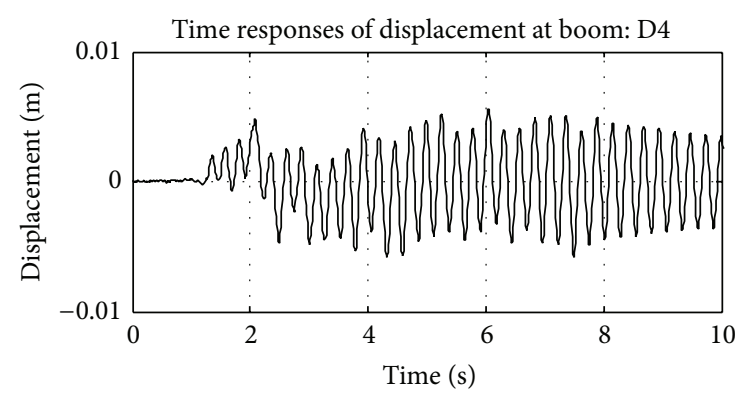

- D4

(e)

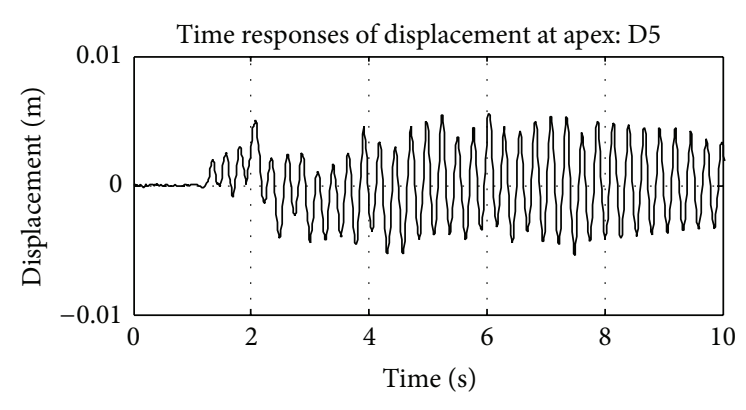

- D5

(g)

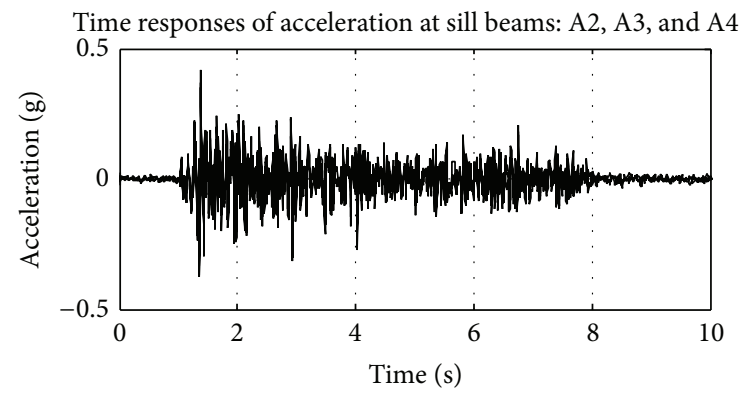

$\mathrm{A} 2$
$-\mathrm{A} 3$
$-\mathrm{A} 4$

(b)

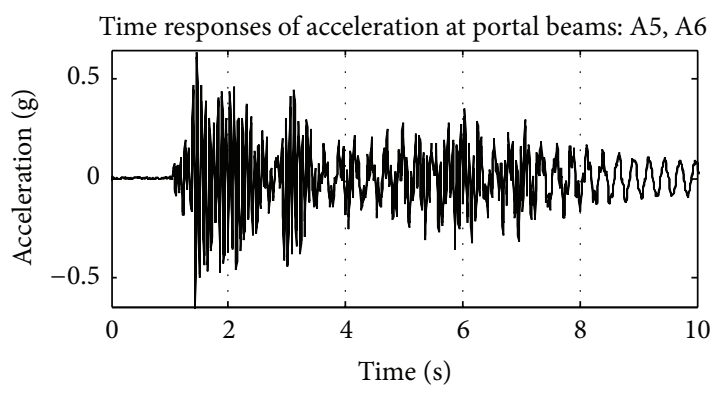

- A5

- A6

(d)

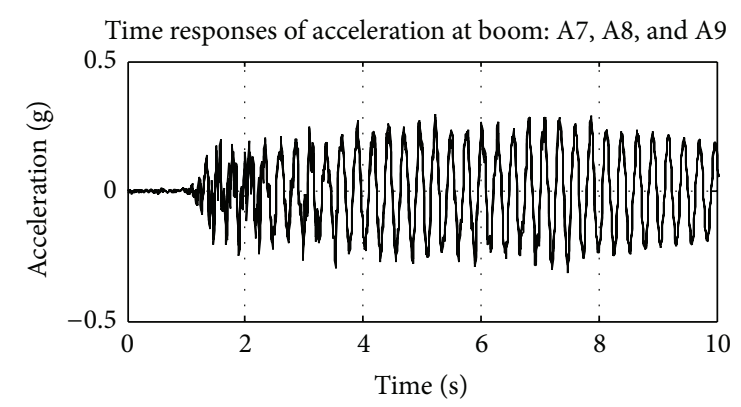

- A7

- A8

- A9

(f)

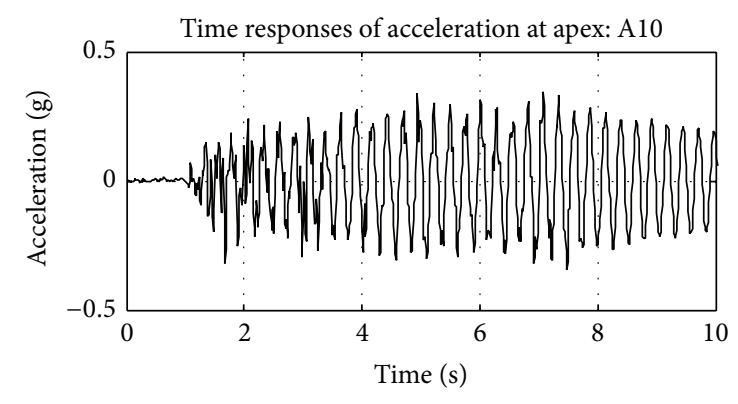

- A10

(h)

FIgURE 4: Time histories of displacement and acceleration at sill beams, portal beams, boom, and apex. 
TABLE 2: PGA and PGD values of shake table test results.

\begin{tabular}{|c|c|c|c|c|c|c|c|c|c|}
\hline \multicolumn{10}{|c|}{ PGA (g) } \\
\hline $\mathrm{A} 1$ & A2 & A3 & A4 & A5 & A6 & A7 & A8 & A9 & $\mathrm{A} 10$ \\
\hline 0.38 & 0.37 & 0.34 & 0.41 & 0.63 & 0.63 & 0.28 & 0.29 & 0.29 & 0.31 \\
\hline \multicolumn{10}{|c|}{ PGD (mm) } \\
\hline & & \multicolumn{2}{|c|}{ D2 } & \multicolumn{2}{|c|}{ D3 } & \multicolumn{2}{|c|}{ D4 } & \multicolumn{2}{|c|}{ D5 } \\
\hline & & \multicolumn{2}{|c|}{3.4} & \multicolumn{2}{|c|}{4.0} & \multicolumn{2}{|c|}{5.2} & \multicolumn{2}{|c|}{5.5} \\
\hline
\end{tabular}

TABLE 3: Mass, stiffness, and the damping values for the models.

\begin{tabular}{cccccccccccc}
\hline & Parameters of mass $(\mathrm{kg})$ & \multicolumn{4}{c}{ Parameters of stiffness (kN/m) } & \multicolumn{4}{c}{ Parameters of damping (Ns/m) } \\
$m_{1}$ & $m_{2}$ & $m_{3}$ & $m_{4}$ & $k_{1}$ & $k_{2}$ & $k_{3}$ & $k_{4}$ & $c_{1}$ & $c_{2}$ & $c_{3}$ & $c_{4}$ \\
\hline 51.2 & 39.6 & 79.8 & 9.3 & 3382.6 & 52.7 & 32.7 & 8.0 & 6766.7 & 105.3 & 65.3 & 16.3 \\
\hline
\end{tabular}

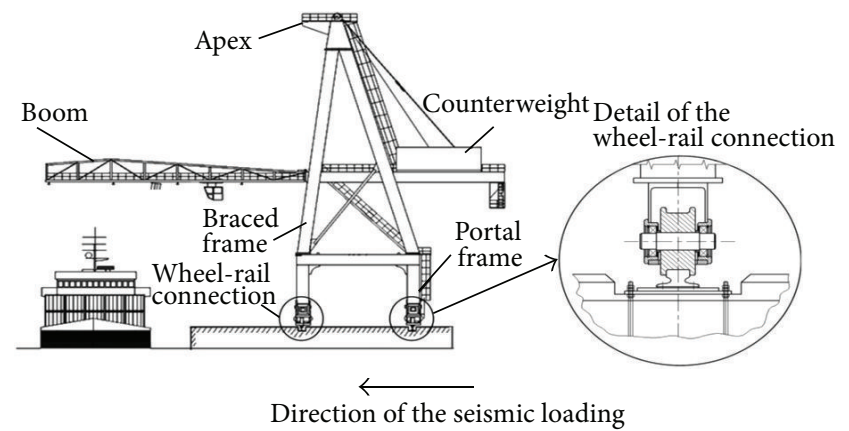

FIGURE 5: Schematic model of the crane with the direction of seismic loading.

are affected uniaxially along the boom which is perpendicular to the rails. (iv) The inertia loads are modelled as lumped masses at the center of mass of the corresponding element. (v) The stiffness and the damping effects at the wheel-rail connection along the boom are modelled. (vi) Crane wheels do not move and gaps in the wheel-rail connection, lateral rail movements, and wheel derailment, matching the boundary conditions of the experimental testing, are ignored.

Lagrange Method is used to observe the equation of motion of the system. General expression of Lagrange method is

$$
\frac{d}{d t}\left(\frac{\partial E_{k}}{\partial \dot{q}_{i}}\right)-\frac{\partial E_{k}}{\partial q_{i}}+\frac{\partial E_{D}}{\partial \dot{q}_{i}}+\frac{\partial E_{P}}{\partial q_{i}}=Q_{i}
$$

Here, $E_{k}$ is the kinetic energy, $E_{p}$ is the potential energy, $E_{D}$ is system damping energy, $Q_{i}$ is external force, and $q_{i}$ is generalised coordinate.

The general expression of the equation of motion of a crane can be represented as follows:

$$
M_{s} \ddot{x}(t)+C_{s} \dot{x}(t)+K_{s} x(t)=E_{w} w(t),
$$

where $x=\left[\begin{array}{llll}x_{1} & x_{2} & x_{3} & x_{4}\end{array}\right]^{T}, E_{w}=\left[\begin{array}{llll}-\left(c_{1} \dot{x}_{0}+k_{1} x_{0}\right) & 0 & 0 & 0\end{array}\right]$ is the matrix of weights for destructives, $w(t)$ is the destructive effect, and $M_{s}, C_{s}, K_{s}$ are mass, damping, and stiffness
TABLE 4: Frequency values of mathematical model.

\begin{tabular}{lcc}
\hline & Frequency $(\mathrm{Hz})$ & \\
$f_{1}$ & $f_{2}$ \\
\hline 2.27 & 4.92 \\
\hline
\end{tabular}

matrices. In equations of energy in Lagrange equation, the results are organized in matrix form and mass, damping, and stiffness matrices are obtained as (3), (4), and (5), respectively. Consider

$$
\begin{gathered}
M_{s}=\left[\begin{array}{cccc}
m_{1} & 0 & 0 & 0 \\
0 & m_{2} & 0 & 0 \\
0 & 0 & m_{3} & 0 \\
0 & 0 & 0 & m_{4}
\end{array}\right], \\
C_{s}=\left[\begin{array}{cccc}
c_{1}+c_{2} & -c_{2} & 0 & 0 \\
-c_{2} & c_{2}+c_{3} & -c_{3} & 0 \\
0 & -c_{3} & c_{3}+c_{4} & -c_{4} \\
0 & 0 & -c_{4} & c_{4}
\end{array}\right], \\
K_{s}=\left[\begin{array}{cccc}
k_{1}+k_{2} & -k_{2} & 0 & 0 \\
-k_{2} & k_{2}+k_{3} & -k_{3} & 0 \\
0 & -k_{3} & k_{3}+k_{4} & -k_{4} \\
0 & 0 & -k_{4} & k_{4}
\end{array}\right] .
\end{gathered}
$$

3.1. Applying Earthquake Motion to the Mathematical Model. The 1940 El Centro Earthquake record was used as input earthquake motions. Data obtained from accelerometers during earthquake are low- and high-pass filtered using the software MATLAB, modeled as a function of time after filtration of the disruptive noise from the recorded signals [16-20].

3.2. Determining the System Parameters. Parameters of the physical model are used in simulation studies of the mathematical model for a better comparison with the shake table model. Mass, stiffness, and damping ratios of the physical model which are also used in the simulation studies are represented in Table 3. 


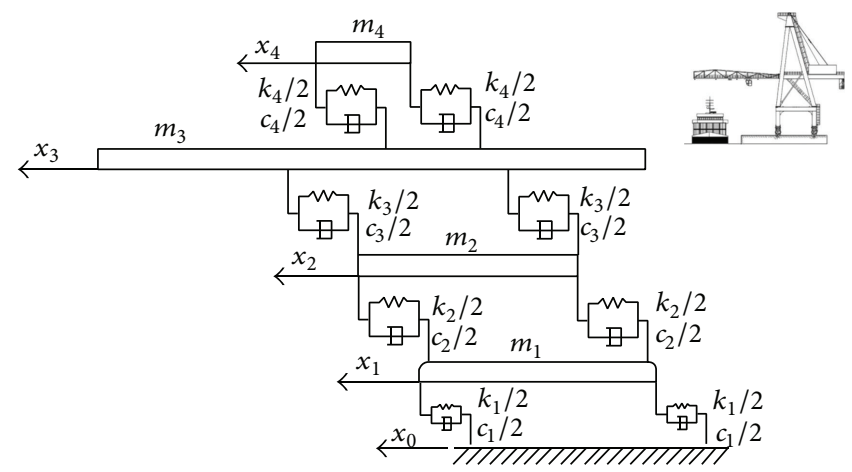

Figure 6: Dynamic Model of the crane under seismic loading.

TABLE 5: PGA and PGD values of mathematical model.

\begin{tabular}{lccccccc}
\hline & \multicolumn{3}{c}{ PGA (g) } & & \multicolumn{3}{c}{ PGD (mm) } \\
$d^{2} x_{1} / d t^{2}$ & $d^{2} x_{2} / d t^{2}$ & & $d^{2} x_{3} / d t^{2}$ & $d^{2} x_{4} / d t^{2}$ & $x_{1}$ & $x_{2}$ & $x_{3}$ \\
\hline 0.31 & 0.62 & 0.21 & 0.28 & 3.6 & 3.9 & 4.8 & 5.2 \\
\hline
\end{tabular}

TABLE 6: Comparison of frequencies.

\begin{tabular}{lcc}
\hline & \multicolumn{2}{c}{ Frequency $(\mathrm{Hz})$} \\
& $f_{1}$ & $f_{2}$ \\
\hline Experiment & 2.36 & 3.94 \\
Simulation & 2.27 & 4.92 \\
Verification (\%) & 3 & 24 \\
\hline
\end{tabular}

3.3. Results of the Mathematical Model. The results of the simulations which were prepared using the mathematical model are given in this part. The first two frequencies obtained from the numerical study are given in Table 4 .

The simulations in time domain prepared using the mathematical model are given in Figure 7. $x_{1}, x_{2}, x_{3}$, and $x_{4}$ are time-dependent changes in displacements at sill beams, portal beams, boom, and apex with respect to $d^{2} x_{1} / d t^{2}$, $d^{2} x_{2} / d t^{2}, d^{2} x_{3} / d t^{2}$, and $d^{2} x_{4} / d t^{2}$ which are time-dependent changes in accelerations at sill beams, middle beams, boom, and apex. Table 5 represents the PGA and PGD values of the mathematical model.

\section{Comparison of the Results}

With the aim of observing the verification of the developed mathematical model with the experimental model in time and frequency domain, the experimental results are compared with the results of the theoretical study.

In the first step, results in frequency domain are compared. Critical frequency values of the physical model were determined with the help of the free vibration tests and frequency values of the mathematical model were determined using the mass and rigidity matrices. Frequency values and verification ratio are given in Table 6.
In the second step, time responses of acceleration and displacement at sill beams, portal beams, boom, and apex under the 1940 El Centro Earthquake excitation both for the physical and the mathematical model are represented in Figure 8. Table 7 represents the comparison of the PGA and PGD values for the related parts of the structure obtained from shake table tests and mathematical model and verification ratio. During the comparison of the measured accelerations with the theoretical acceleration, the average value of the measured accelerations on the corresponding element was used. Experimental and mathematical models responses at many members are in good agreement.

\section{Conclusion}

In this study, it was determined that a mathematical model provides reasonable results based on the shake table tests results. The mathematical model can be used in the future to study the seismic response of container cranes. Due to the need of performing several analyses with different earthquake excitations to assure the design safety, using practical engineering solution as a mathematical modeling is an important feature in earthquake engineering avoiding the use of complex finite element meshes. Depending on the specified reasons, it can be said that using the simple and effective mathematical model causes realistic results and prevents time consuming.

With the help of the mathematical model, taking structural precautions for cranes will be possible. The mathematical model can also be used as a crane model in activepassive vibration control studies so that it will be available for researchers in vibration control studies to develop new detailed control algorithms. This study can lead to more developed numerical studies in the future. 
TABLE 7: Comparison of the PGA and PGD values of mathematical model and shake table test.

\begin{tabular}{lcccccccc}
\hline & & \multicolumn{2}{c}{ PGA $(\mathrm{g})$} & & \multicolumn{2}{c}{ PGD (mm) } \\
& Sill beam & Portal beam & Boom & Apex & Sill beam & Portal beam & Boom & Apex \\
\hline Experiment & 0.37 & 0.63 & 0.28 & 0.31 & 3.4 & 4.0 & 5.2 & 5.5 \\
Simulation & 0.31 & 0.62 & 0.21 & 0.28 & 3.6 & 3.9 & 4.8 & 5.2 \\
Verification (\%) & 16 & 1 & 25 & 9 & 5 & 2 & 7 \\
\hline
\end{tabular}

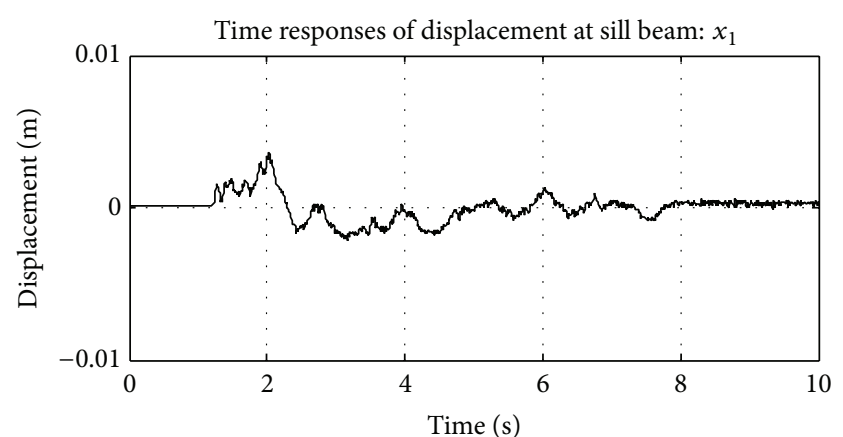

(a)

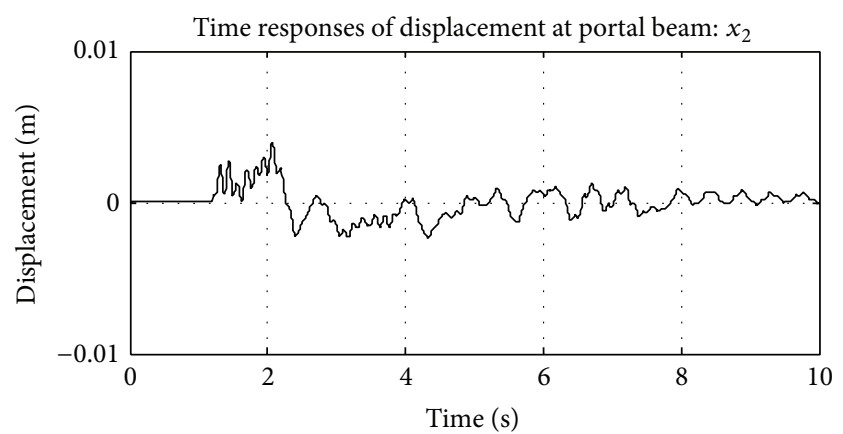

(c)

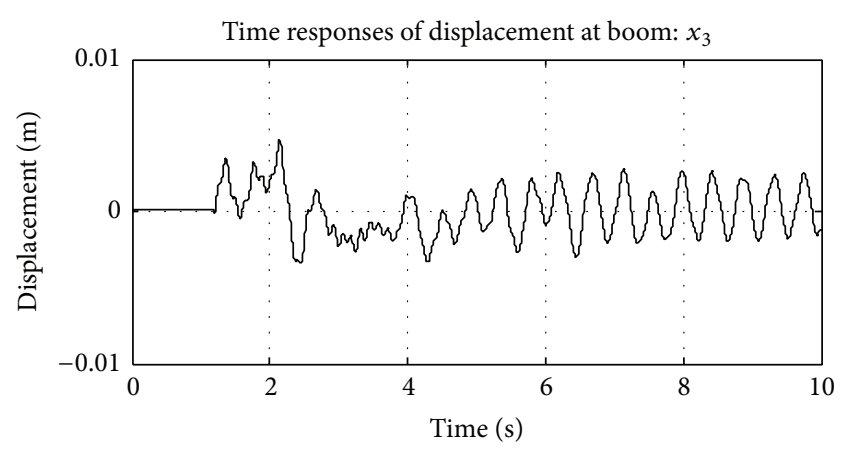

(e)

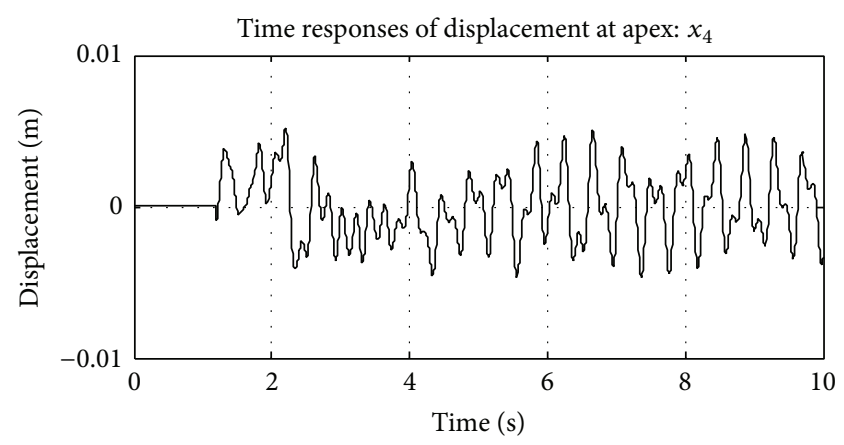

(g)

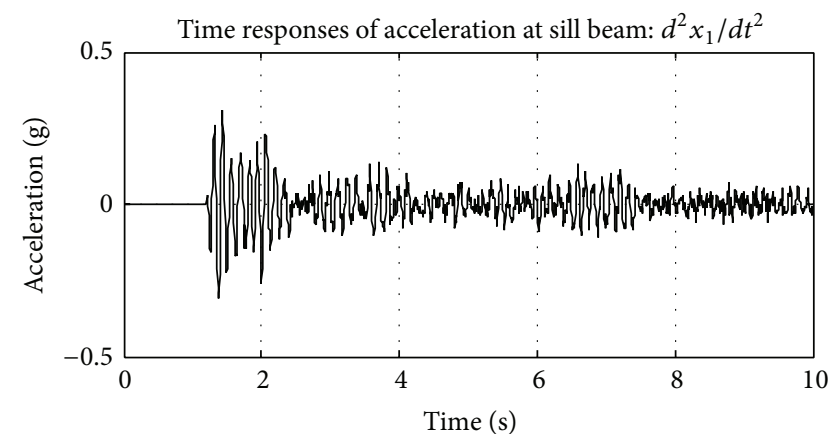

(b)

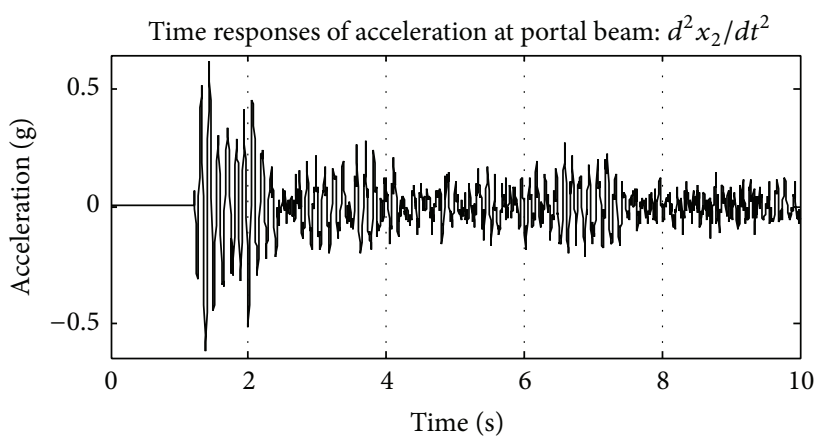

(d)

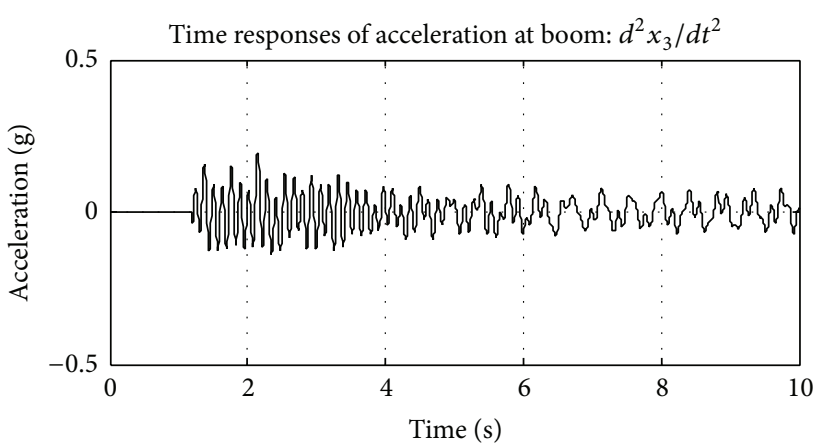

(f)

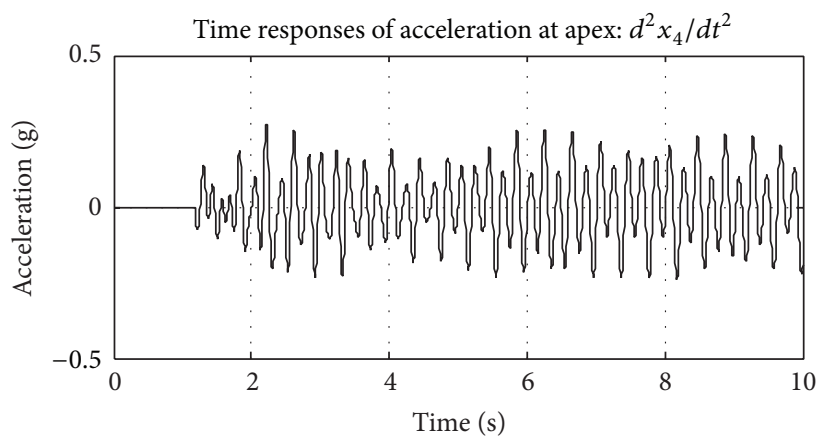

(h)

FIGURE 7: Time histories of displacement and acceleration at sill beams, middle beams, boom, and apex. 


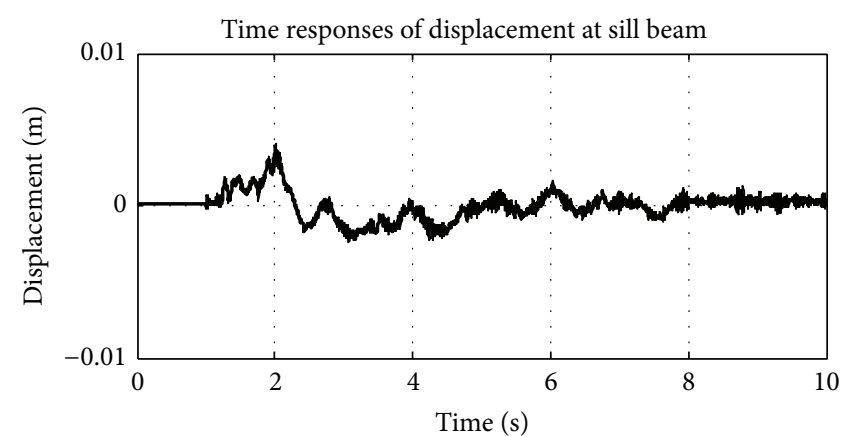

(a)

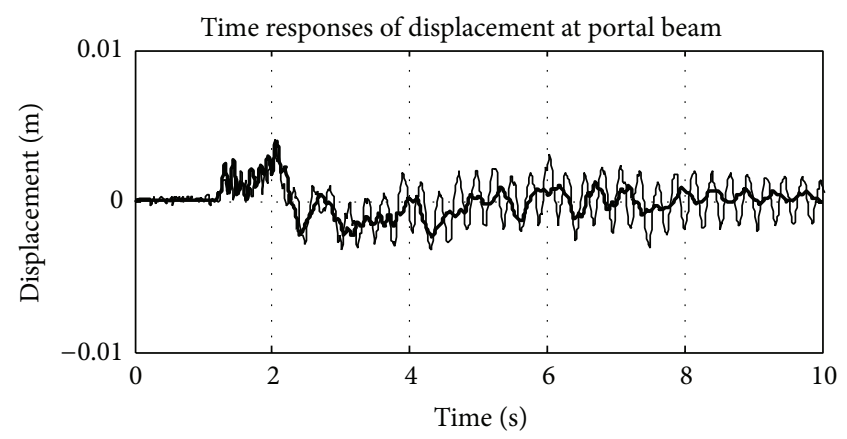

(c)

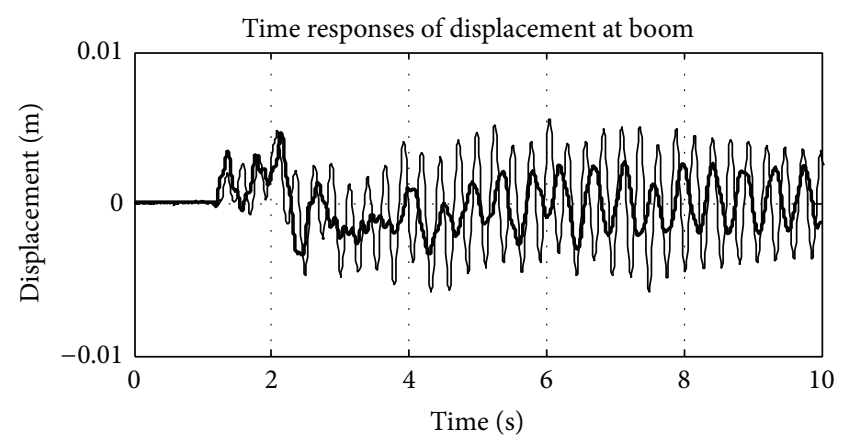

(e)

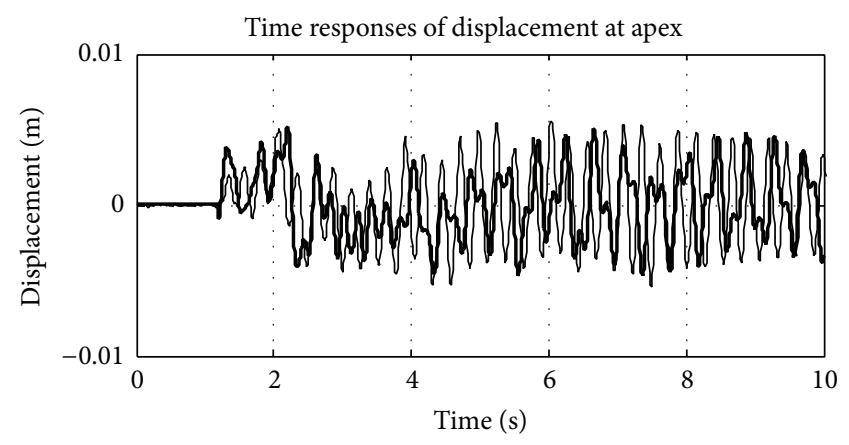

Mathematical model Shake table test

(g)

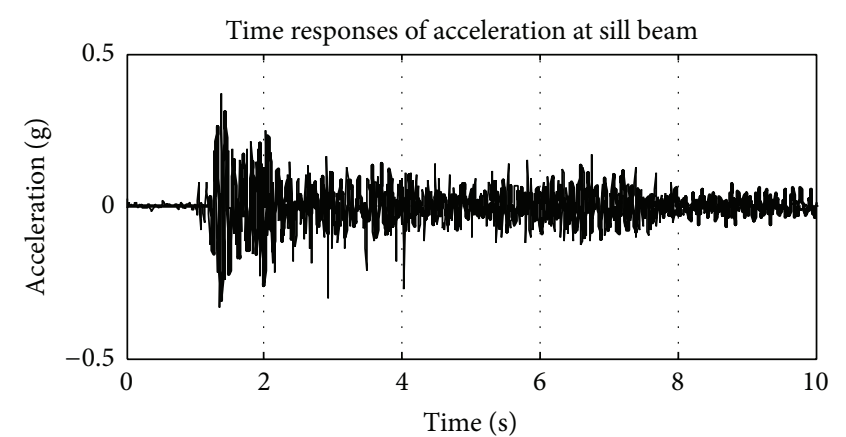

(b)

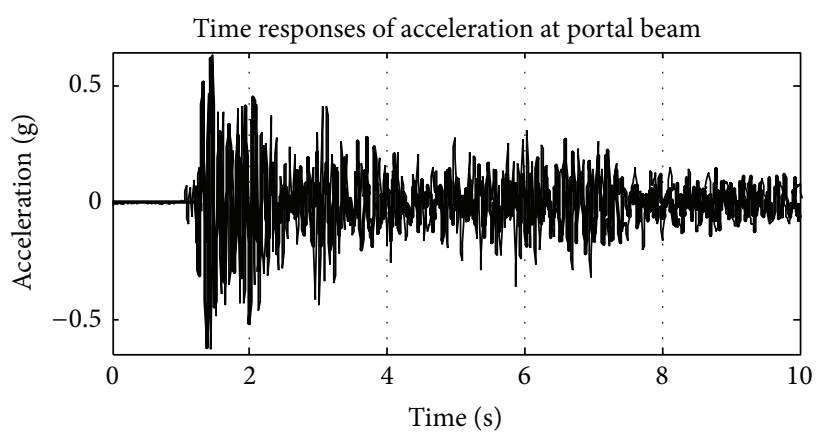

(d)

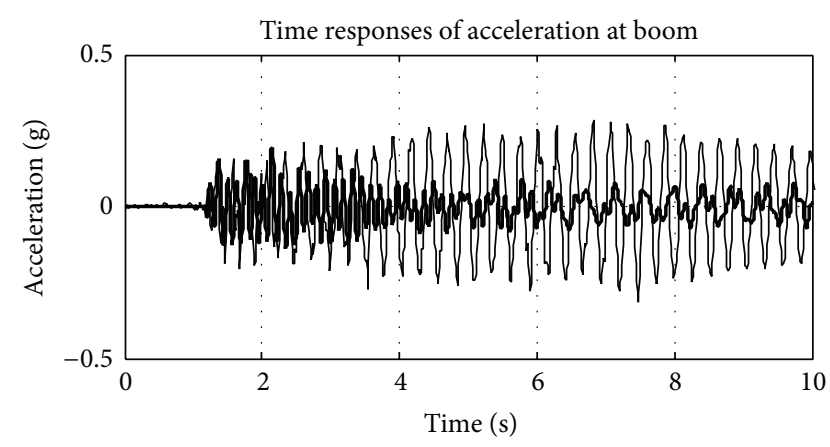

(f)

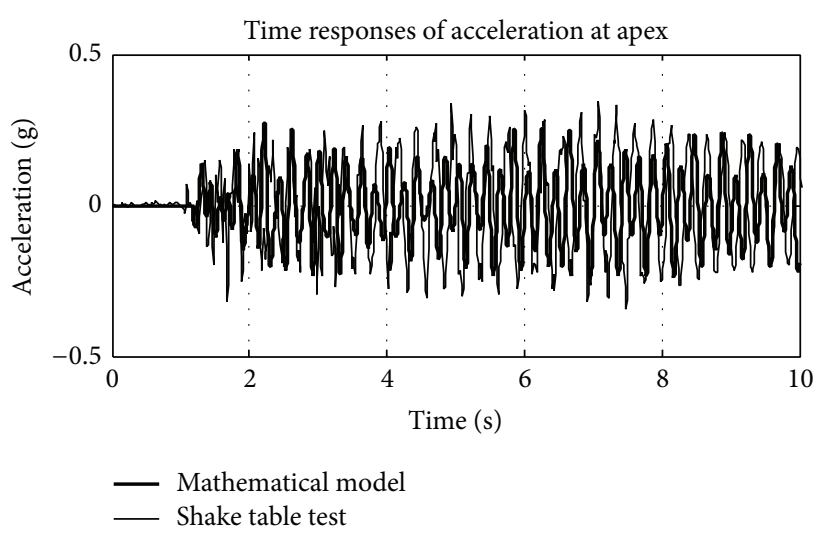

(h)

FIGURE 8: Comparison of the mathematical model and shake table test results. 


\section{Conflict of Interests}

The authors declare that there is no conflict of interests regarding the publication of this paper.

\section{Acknowledgment}

This research has been funded by a grant from the Division of Scientific Research Projects of Yildiz Technical University, Istanbul, Turkey. The authors greatly indebted to the financial support obtained from this institution.

\section{References}

[1] T. Kanayama and A. Kashiwazaki, "A study on the dynamic behavior of container cranes under strong earthquakes," Seismic Engineering, vol. 364, pp. 276-284, 1998.

[2] T. Kanayama, A. Kashiwazki, N. Shimizu, I. Nakamaura, and N. Kobayashi, "Large shaking table test of a container crane by strong ground excitation," Seismic Engineering, vol. 364, pp. 243-248, 1998.

[3] E. Soderberg and M. Jordan, "Seismic response of jumbo container cranes and design recommendations to limit damage and prevent collapse," in Ports 2007: 11th Triennial International Conference on Ports, San Diego, California, United States, pp. 110, ASCE, 2007.

[4] B. Koshab and L. Jacobs, "Seismic performance of container cranes," in Seismic Risk Management for Port Systems, NEESR Grand Challenge Third Annual Meeting, Georgia Institute of Technology, Atlanta, Ga, USA, 2008.

[5] L. Jacobs, R. DesRoches, and R. T. Leon, "Shake table testing of container cranes," in Proceedings of the 14th World Conference on Earthquake Engineering (WCEE '08), Beijing, China, October 2008.

[6] N. Kobayashi, H. Kuribara, T. Honda, and M. Watanabe, "Nonlinear seismic responses of container cranes including the contact problem between wheels and rails," Journal of Pressure Vessel Technology, vol. 126, no. 1, pp. 59-65, 2004.

[7] T. Sugano, M. Takenobu, T. Suzuki, and Y. Shiozaki, "Design procedures of seismic-isolated container crane at port," in Proceedings of the 14th World Conference on Earthquake Engineering (WCEE '08), Beijing, China, 2008.

[8] A. Sagirli and C. O. Azeloglu, "Investigation of the dynamic behaviors of cranes under seismic effects with theoretical and experimental study," Advanced Materials Research, vol. 445, pp. 1082-1087, 2012.

[9] A. Sagirli, C. O. Azeloglu, R. Guclu, and H. Yazici, "Self-tuning fuzzy logic control of crane structures against earthquake induced vibration," Nonlinear Dynamics, vol. 64, no. 4, pp. 375384, 2011.

[10] C. O. Azeloglu, Modeling of the behaviors of cranes under seismic effect and vibrations active control [Ph.D. thesis], Yildiz Technical University, Istanbul, Turkey, 2012.

[11] C. O. Azeloglu, A. Sagirli, and A. Edincliler, "Mathematical modelling of the container cranes under seismic loading and proving by shake table," Nonlinear Dynamics, vol. 73, no. 1-2, pp. 143-154, 2013.

[12] E. M. Abdel-Rahman, A. H. Nayfeh, and Z. N. Masoud, "Dynamics and control of cranes: a review," Journal of Vibration and Control, vol. 9, no. 7, pp. 863-908, 2003.
[13] Z. N. Masoud, "Effect of hoisting cable elasticity on anti-sway controllers of quay-side container cranes," Nonlinear Dynamics, vol. 58, no. 1-2, pp. 129-140, 2009.

[14] M. F. Daqaq and Z. N. Masoud, "Nonlinear input-shaping controller for quay-side container cranes," Nonlinear Dynamics, vol. 45, no. 1-2, pp. 149-170, 2006.

[15] N. A. Nayfeh and W. T. Baumann, "Nonlinear analysis of timedelay position feedback control of container cranes," Nonlinear Dynamics, vol. 53, no. 1-2, pp. 75-88, 2008.

[16] N. Yagiz, "Vibration control of a building with ATMD under earthquake excitation," International Journal of Applied Mechanics and Engineering, vol. 8, no. 1, pp. 117-123, 2003.

[17] R. Guclu and H. Yazici, "Fuzzy logic control of a non-linear structural system against earthquake induced vibration," JVC: Journal of Vibration and Control, vol. 13, no. 11, pp. 1535-1551, 2007.

[18] R. Guclu and H. Yazici, "Vibration control of a structure with ATMD against earthquake using fuzzy logic controllers," Journal of Sound and Vibration, vol. 318, no. 1-2, pp. 36-49, 2008.

[19] R. Guclu and H. Yazici, "Seismic-vibration mitigation of a nonlinear structural system with an ATMD through a fuzzy PID controller," Nonlinear Dynamics, vol. 58, no. 3, pp. 553-564, 2009.

[20] R. Guclu and H. Yazici, "Self-tuning fuzzy logic control of a nonlinear structural system with ATMD against earthquake," Nonlinear Dynamics, vol. 56, no. 3, pp. 199-211, 2009.

[21] S. Iai, "Port structures," in Earthquake Engineering Handbook (New Directions in Civil Engineering), C. Scawthorn and W. Chen, Eds., chapter 27, CRC Press, Boca Raton, Fla, USA, 2003. 

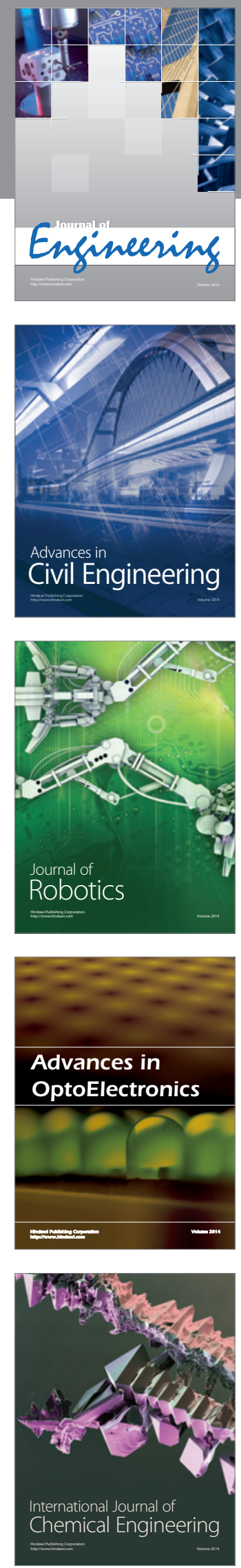

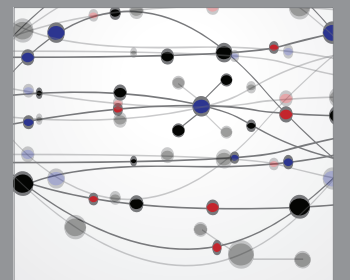

The Scientific World Journal
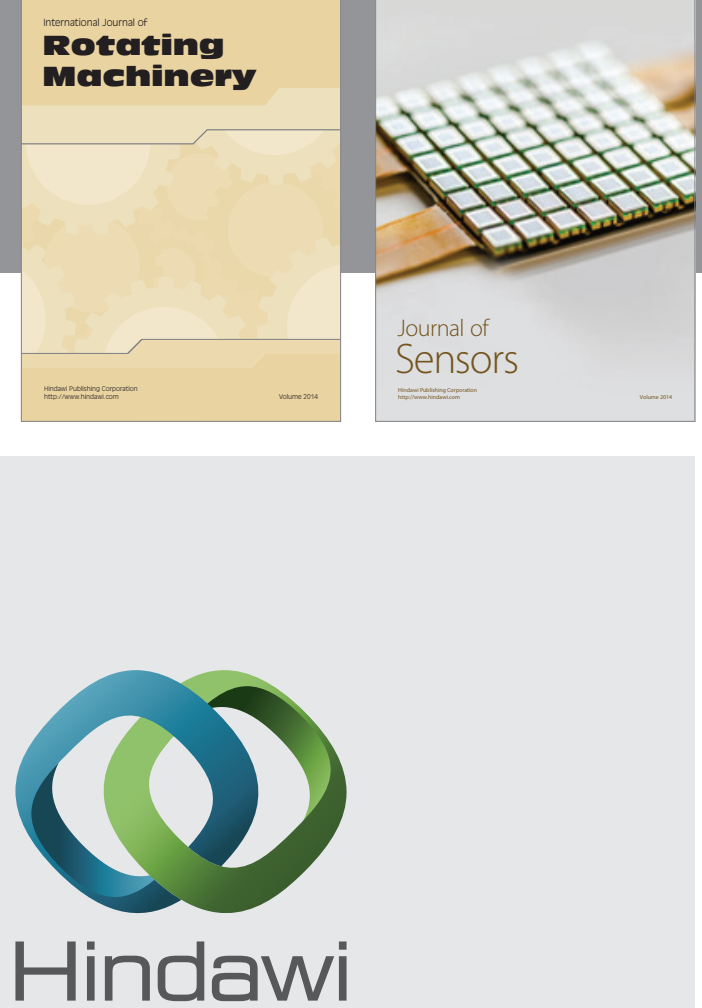

Submit your manuscripts at http://www.hindawi.com
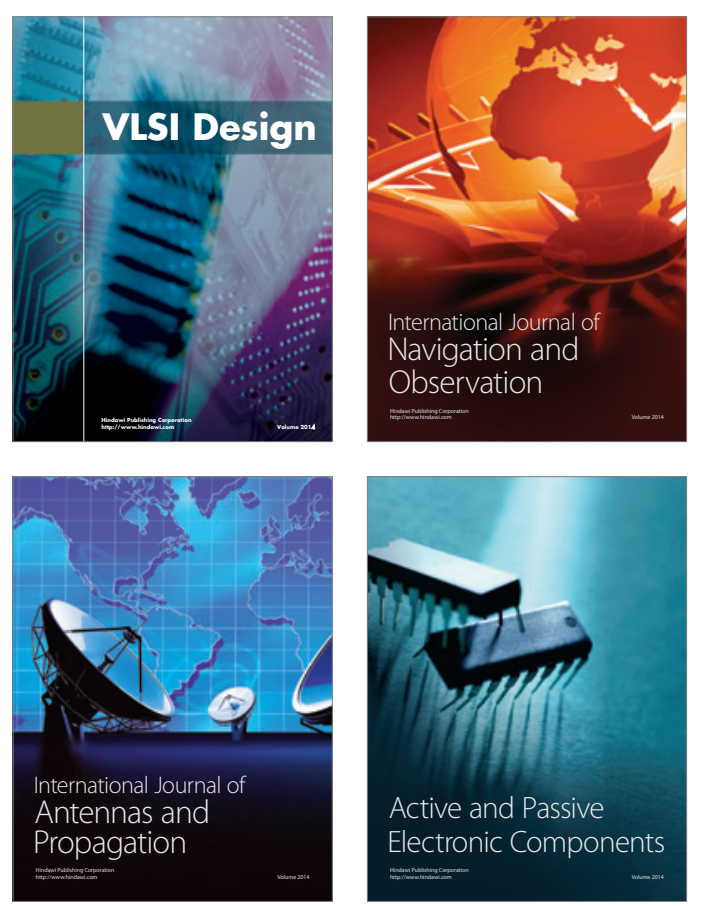
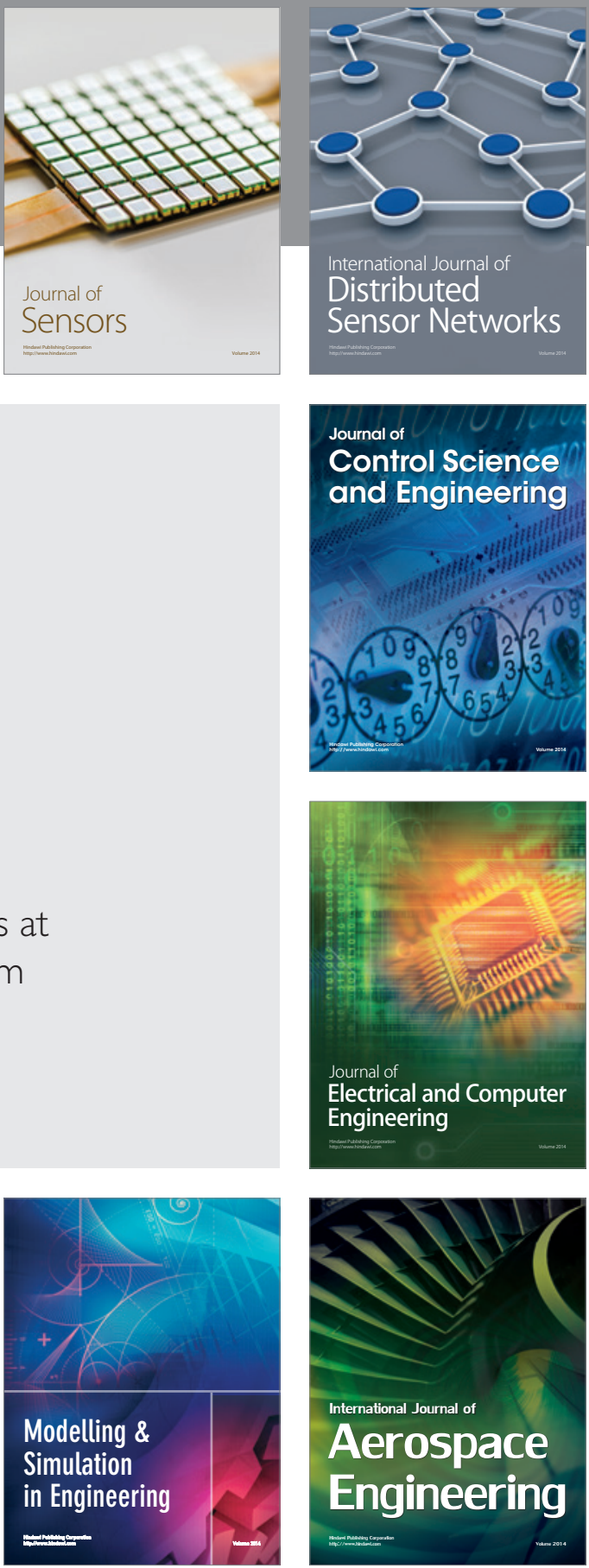

Journal of

Control Science

and Engineering
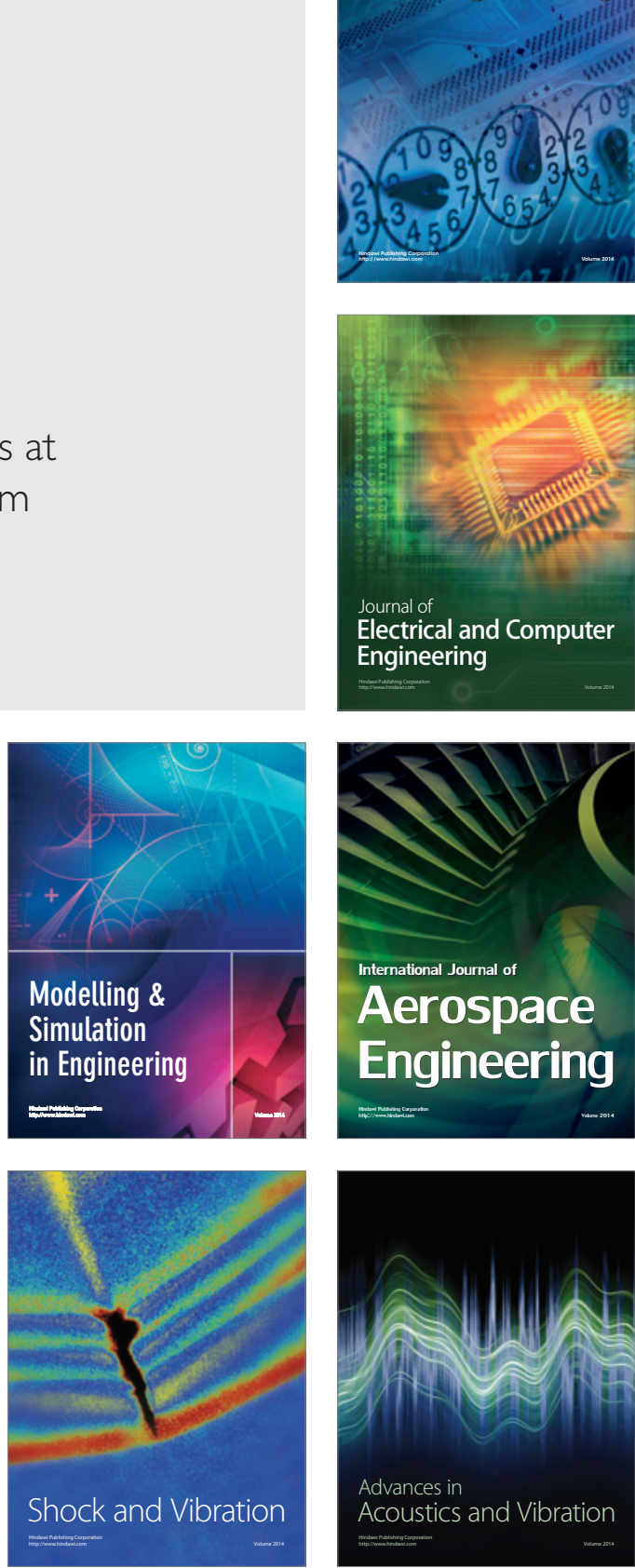